drying polymer solutions were reported by $\mathrm{R}$. B. Ingalls (North American Aviation) and L. A. Wall (National Bureau of Standards, Washington). Surface properties were also considered by V. B. Kazanskii and G. B. Pariiskii (Moscow), who were able to obtain electron spin. resonance spectra of free radicals adsorbed on surfaces of insulators but not of semiconductors.

The electron spin resonance spectra of organic diradicals such as substituted methylenes were reported by W. A. Yager, K. W. Murray, G. Smolinsky, A. M. Trozzolo and E. Wasserman (Bell Telephone Laboratories).

Chemical reactions studied in the solid-state using electron spin resonance spectroscopy included the benzene photosensitized decomposition of hydrocarbons (N. V. Fock, B. N. Shelimov and V. V. Veovodskii (Moscow)), the reaction of ethylene or oxygen using an ingenious rotating cryostat (J. E. Bennett and A. Thomas (Shell, Thornton)), and the photolysis of methyl iodide at $\lambda=2537 \AA$, where the methyl radicals rapidly extract hydrogen from the methylcyclohexane cage (J. M. Flournoy, H. S. Judeikis (Aerojet, California)).

Chemical analysis was used by R. H. Duffett and G. J. Minkoff (British Petroleum, Sunbury) to examine the reaction of hydrogen and deuterium atoms with solid olefines. Fluorescence spectra of benzyl radicals in cyclohexane glasses were studied by L. Grajcar and S. Leach (Orsay, Paris) to obtain information about the structure of the solid-state. For their studies oxygen in liquid and solid argon, A. M. Bass and H. P. Broida (National Bureau of Standards, Washington) used ultra-violet spectroscopy. The formation and decomposition of purple sulphur at low temperatures was illustrated with a colour film by F. O. Rice (Notre Dame, Indiana).

It is more difficult to maintain significant concentrations of reactive species in the liquid state than in the solid phase. Three of the papers, however, reported electron spin resonance investigations of short-lived radicals under liquid conditions. The use of a fast-flow system in which the reactants were mixed close to the sampling cell was reported by P. L. Kolker, T. J. Stone and W. A. Waters (Oxford), who produced aromatic radicals by oxidation of phenols, and by W. T. Dixon and R. O. C. Norman (Oxford), who formed various aliphatic radicals using titanous salt-peroxide systems. L. H. Piette (Varian, California) showed that both rapid response and good sensitivity would be obtained with an electron spin resonance spectrometer on a statistical basis. Electron spin resonance studies of radicals produced by the photolysis of electron-donor-acceptor system were reported by C. Lagercrantz (Göteborg) and the spectra of terphenyl anions by K. H. Hausser, L. Mongini and R. van Steenwinkel (Euratom, Ispra). The production and properties of ketyl radicals formed by polarographic reduction were described by Z. R. Grabowski and M. K. Kalinowski (Warsaw).

The importance of diffusion of radicals in solution was discussed in papers by J. E. Guillet and J. C. Gilmer (Tennessee Eastman) and A. D. Osborne and G. Porter (Sheffield) respectively. The former showed that solvent cages are important in the decomposition of diacyl peroxides and that the activation energies for radical escape from a cage and for diffusion are identical. The latter workers showed, by studying the decay of active species in solvents of different viscosity, that the Debye equation is valid when the reacting species do not differ greatly in size from the solvent molecules.

This stimulating meeting was assisted by the Royal Society, by many British industrial firms, and by the provision of transport for many North American Delegates by the United States Air Force. It is planned to hold the seventh Symposium in 1965 in Italy, probably in Venice. B. A. Thrush

\title{
INSPECTION OF ALKALI AND CEMENT WORKS
}

$\mathrm{T}$ HE ninety-ninth annual report on alkali, etc., works in England and Wales covering the year 1962 by the Chief Inspector * notes the extension by the responsibilities of the inspectorate by the Alkali, etc., Works Order, 1961, to cover control of emissions from calcination of black liquors from paper manufacture and from operations involving uranium, beryllium, selenium and their compounds. At the end of $1962,2,077$ works were registered under the Act, involving the operation of 3,247 separate processes, and 10,768 visits and inspections were made during the year, including 140 special visits by the Chief and Deputy Chief Inspectors. During the inspections, 4,331 quantitative analyses were made of gases evolved from processes, compared with 6,992 in 1961, but the latter total included 3,065 tests taken during a special investigation into emissions from the salt glazing of earthenware.

In addition, 647 special samples were taken and submitted for analysis to the Government Chemist. Specific complaints investigated during the year, largely at the request of local authorities, concermed 297 works, compared with 283 in 1961, 292 in 1960 and 354 in 1959, and of these 297 works 233 were registered under the Act, and the complaints were most numerous against gas and coke works (47), ceramic works (41), electricity works (33), iron and steel works (27), aluminium works (14) and cement works (13). The degree of justification for complaint varied, and once again was most bitter against some of the smaller works. There was also some general

* Ministry of Housing and Local Government; Scottish Development Department. Alkali, etc., Works Regulation Act, 1906, and Alkali, etc. Works Orders 1928-1961. Alkali, etc., Works Regulation (Scotland) Acts, 1906,1951 , and Alkali, etc., Works (Scotland) Orders, 1952 and 1958) 1962. Pp. 75. (London: H.M.S.O., 1963.) 5s. net. complaint against overall emission in particular areas rather than against any specified works, and of the 16 examples include the blue-brick making area of Staffordshire and The Thames and Medway cement-making areas. Listed infractions, numbering 10, were again confined to the pre-1958 processes and remedies were applied on formal notification by the inspector without institution of proceedings. The root cause of the trouble in the Thames cement making area was the approaching exhaustion of available Eocene clay supplies in North Kent and the consequent use of ever-increasing proportions of estuarine clay from the Cliffe marshes, and the resulting increased dust burden in the kiln gases has in turn led to overloading and erratic operation, or even failure, of electrical precipitates. Planning consent was sought to win sufficient Eocene clay from Essex to replace all the Cliffe clay in use and at the end of the year only one of the four works on the south bank of the Thames was on Cliffe clay. The report includes an interesting historical review of the evaporation of lime in open pans, a process for common salt now practically out of use and there is also a brief discussion of the problem of emissions from the Trophas steel con. verter. Although the Inspectorate is still much preoccupied with grit, etc., emissions from the intermediate-sized coal-fired power stations, considerable progress can be recorded in modernization and replacement of grit and dust collection plant, and there are reasonable grounds to believe that such emissions will be reduced to a satisfactory level, but concern is still expressed over the minimization of emissions of acid-soot from oil-fired power stations.

The annual report for 1962 of the Chief Inspector for Scotland, published under the same cover, records a decrease in the number of registered premises from 297 
to 285 , chiefly due to closure of gas works by extension of the grid system of distribution. The 575 visits of inspection included 36 by the Chief Inspector and there were 142 further miscellaneous visits and 64 visits not under the Acts. The dust-testing team from the Department of Scientific and Industrial Research completed during the year 20 months of its three-year contract period and made 28 tests of dust emission from registered premises. The work has shown that circumstances in field work may require substantial modification of procedures laid down in accepted standard methods for dust measurement. Maintenance of operation of plants to prevent discharges of noxious and offensive gases from registered premises was generally satisfactory.

\section{THE BRITISH COKE RESEARCH ASSOCIATION}

$\mathrm{T}$ HE nineteenth annual report of the British Coke Research Association* is noteworthy for the record of continued expansion and progressive research undertaken during the year 1962. One immediate objective has been the direction of attention to the more practical aspects of the results of research. This has been stimulated by the Association's participation in the Special Assistance to Industry Scheme, sponsored by the Department of Scientific and Industrial Research. The use of films, a fully equipped mobile laboratory and an expansion of the technical liaison and advisory services are now additional means of 'putting over' the great amount of 'know-how' which has been learned during past years about the correct methods of sampling, sample-preparation, physical testing and analysis of coke.

Naturally, with the competitive challonge of alternative fuels and of alternative methods of metallurgical practice, the question of the supply and demand of fuels manufactured from coals must constantly be a matter for vigilance and close examination. In recent years there have been changes in the demand for blast-furnace coke, partly as a result of the reduction in the production of steel. The demand has also fallen for the technical reason that blast furnaces now use less coke per ton of pig iron produced, because of the extension and improvement of sinter practice and the successful application to blast. furnace operation of the injection of fuel oil and of powdered coal. Given, however, a reasonable level of expansion of the national economy, the demand should not change much in coming years. Moreover, it has been concluded that the blast furnace will remain the principal producer of iron in the foreseeable future. While the coke-oven process, with improvements, will continue to be used to meet the demand for blast-furnace coke, there is, however, a possibility of a new process being developed, using cheaper coal and giving a product of uniform shape and size, described as a 'formed coke' which might prove to be more economic in use than the conventional product. Depending on capital and running costs, such a process might be economically competitive with the coke-oven process. The development of a formed-coke process, involving the erection of costly prototypes, would undoubtedly prove to be enormously expensive and might possibly be best pursued by international co-operation. The Russians and the Poles, among others, have devoted much time and money in recent years to this question. It is very satisfactory to learn that the British Coke Research Association is well aware both of the possibilities and the difficulties of adopting such a process, which in the event may best be suited to localities of the world remote from supplies of good coking coal.

A formed-coke process should provide means for the supply of a solid fuel tailored to the future requiroments of the blast furnace; but the Association in fact is mounting a two-headed attack on this difficult question of new typos of fuel for the iron and steel industry. The other possibility which is being investigated is that of influencing the proporties and more particularly the size of coke produced in the conventional coke-oven by controlling

* Nineteenth Annual Report of the British Coke Research Association, 1962. Chesterfield, Derbyshire. the fissuring process during carbonization. Undoubtedly news of developments in both these fields will be awaited with great interest.

Passing to the record of the research achievement, painstaking effort, not always rewarded with equivalent positive result and calling for much detailed experiment, has continued in the general study of additions to the coal blend for carbonization. Examples of the additions in question are coal-tar pitches, petroleum residues, breeze and heavy petroleum oil. Nevertheless, results have arisen that are worth all the effort. Thus in the case of the possible substitution of breeze for a Welsh coal it was found that 3 per cent of fine breeze could replace the most costly component of the blend while providing coke of similar characteristics. Again, in respect of the use of sodium carbonate, the addition of which is known to improve the reactivity of coke for domestic purposos, with a 0.75 per cent addition of this salt before coking not only was the reactivity improved but also the size of the coke and the resistance to impact increased, though the resistance to abrasion fell considerably. Other features of economic importance have been revealed, for example, the determination of the end-point of carbonization, at which the 'soaking' of the charge has reached its optimum in terms of the useful properties developed in the coke.

The provision of means for carrying out coking trials at various ranges of capacity, from a full scale involving a 10 tons charge to as small a quantity as $15 \mathrm{lb}$., has apparently paid off handsomely, for one reads of trials that are necessary in the large oven and others of equal importance being run in the small ones. Further trials of new blends may be run in the large oven, when it has been established in the small ovens that an improvement is likely and that there is no danger of coking pressures large enough to damage the oven.

Since the earliest use of coke for iron production, the demand for metallurgical coke of low sulphur content has persisted and with the progressive exhaustion of the best coking coals the problem of sulphur impurity has renaained of growing importance. More particularly does the difficulty arise in respect of the behaviour of the organic sulphur constituents. The objective is, of course, to discover whether these reactions may ultimately be capable of being controlled. In a very complete examination of the sulphur-carbon complexes to be found in coke, involving the most modern techniques, electronspin resonance measurements among others, it has been concluded tentatively that the surface sulphides make an important contribution to the organic sulphur content of coke and that dehydrogenation by sulphur, and the interaction of sulphur with free radicals present in the coke, contribute to the formation of these complexes during the coking process. Their preservation in the coke seems to depend on their being of stability greater than that of their carbon-oxygen counterparts.

The A.pplied Studies Laboratory at Chesterfield has been concerned particularly with problems bearing on the thermal behaviour and fissuring of coke, methods of analysis and measurement and the use of oven coke in domestic appliances. The housewife requires a coke of ready combustibility, that is to say, she wants a fuel that 